AÜiFD 47 (2006), sayı l, s. 1-10

\title{
İman Esasları Hakkında Bir Değerlendirme
}

\author{
SABRI ERDEM \\ Doç. Dr., ANKARA Ü. İLAHIYAT FAKÜLTESI \\ e-posta: erdem@divinity.ankara.edu.tr
}

\begin{abstract}
A Consideration on Pillars of Faith. The number of the pillars of faith, what they are, and how they should be understood are related to the conception of 'the pillars of faith'. The conception of 'the pillars of faith' is, in turn, related to the method employed in the problem of faith and the solutions offered in this method. Concerning the problem of faith, the hadith school employed rationalism having a concrete character as a method while the kalam school used rationalism having an abstract character as a method. The character of the solution offered using a rationalism having a concrete character as a method becomes concrete while that of the solution offered employing a rationalism having an abstract character as a method becomes abstract.In other words, both the hadith school and the kalam school identify and construe the pillars of faith based on the criteria they establish and the rationalism they employ as a method. Yet, when we attempt at understanding the Qu'ran in terms of semantics, the Qu'ran does not contain any knowledge related to the determination and construing of the pillars of faith. In other words, the solutions provided with respect of the pillars of faith are interpretations. Therefore, any differentiation in this respect is natural.
\end{abstract}

\section{Key words}

The pillars of faith, rationalism having an abstract character, rationalism having a concrete character, semantic method.

Bazılarına göre iman esaslarının sayısı, hakkında farklılaşmanın olmaması gerekir. Halbuki İslâm düşüncesinde meselâ hadisçilerle ehl-i sünnet kelâmcıları iman esaslarının sayısı, neler olduğu ve anlaşılması hususunda fark1 görüşler ortaya koymuşlardır. Biz de bu yazımızda söz konusu farklılıkların nereden ve nasıl ortaya çıtı̆̆ğı ve dolayısıyla da bunun normal karşılanması gerektiğini göstermeye çalışacă̆ız.

İman esaslarının sayısı, neler olduğu ve anlaşılma biçimi, 'iman esasları' anlayışıyla ilgilidir. 'İman esasları' anlayışı da iman probleminde kullanılan 
metod ve bu metoda göre oluşturulan çözümlerle ilgilidir. İman probleminde hadisçiler metod olarak somut karakterli akılcılığı, kelâmcılar da soyut karakterli akılcılığı kullanmışlardır. Metod olarak somut karakterli akılcılık kullanıldığında ortaya konan çözümün karakteri somut olurken, metod olarak soyut karakterli akılcılık kullanıldığında ortaya konan çözümün karakteri soyut olmuştur. Zira itikadî bir problemde kullanılan metod ile probleme getirilen çözüm arasında karakter bakımından uygunluk vardır. Bu bakımdan öncelikle somut ve soyut karakterli akılcılığın ne olduğu üzerinde kısaca durulacaktır.Sonra da hadisçilerle kelâmcıların iman probleminde kullandıkları akılcılık ve buna uygun olarak getirdikleri çözümler incelenecektir.Bunlarla bağlantılı olarak 'iman esasları' anlayışı yani iman esaslarının sayısı, neler olduğu ve nasıl anlaşıldığı tespit edilecektir.

Somut karakterli akılcılık ile soyut karakterli akılcılık hakkında öncelikle akıl kelimesinin lugat anlamından hareketle bilgi vermek mümkündür. Akıl kelimesi lugatta tutmak anlamında şöyle kullanılır: "Akale'd-devau batnehu' ${ }^{1}$.Yani söz konusu ilaç, o kimsenin bozuk olan bağırsaklarına iyi gelmiş ve onu bu durumdan kurtarmıştır. 'Kad u'tukile lisanuhu' şeklindeki kullanım da kişinin konuşmaktan menedildiğini anlatır. Bu kullanımdan hareketle insanı hapseden ve onu hevasından döndüren şey için akıl kelimesi kullanılmıştır. Yani akla, sahibini tehlikelerden koruduğu için akıl denmiştir. Keza lugatta "Akaltu'l- be'ire' şeklindeki kullanım devenin ayaklarının bağlanmasını anlatır. Bu kullanımdan hareketle işini ve düşüncesini birleştiren kişi anlamına gelen 'raculun 'akilun' kullanımı söz konusu olmuştur ${ }^{2}$.

Böylece akıl kelimesinin lugat anlamını göz önüne aldığımızda bir şeyin bağlanması ve birden fazla şeyin birbirine bağlanması gibi anlamlar söz konusu olmaktadır. Bu, aklın somut karakterli bir biçimde kullanılması anlamına gelmektedir. Zira böyle bir durumda meselâ birden çok şeyin birbirine bağlanması ve bir bütünü oluşturması söz konusu olmaktadır. Diğer taraftan lugat anlamında aklın bir şeyi diğer bir şeyden menetmesini göz önüne alarak onun bir şeyi diğerinden ayırdığı ve soyutladığı gibi bir anlama geldiğini söylememiz mümkün olacaktır. Bu yüzden akla insanı diğer canlılardan ayıran şey denmiştir. Bu da aklın soyut karakterli olarak kullanılması anlamina gelmektedir.

İtikadî problemlerle ilgili olarak somut ve soyut karakterlilikten bahsedilebilir. Somut karakterlilikte akılcılık ve varlık anlayışları ayrı olmayıp birbirine bağlıdır ve birbirini gerektirir. Zira somut karakterlilikte akılcılı̆̆ın belli

İbn Manzûr, Lîsanu'l-'arab, c.: 1-15, Beirut 1990, 'AQL maddesi

A.y. 
bir şekli yani formu yoktur. Buna mukabil soyut karakterlilikte akılcılık ile varlık anlayışları birbirinden ayrılabilir. Zira şekli muhtevadan ayırmak mümkündür. Bu yüzden soyut karakterli akılcılığın belirleyiciliğinden söz edilebilir.Bir başka ifadeyle akılcılıktan varlığa doğru bir gidiş vardır.Dolayısıyla akılcılıktan varlığa ve varlıktan akılcılığa doğru olmak üzere çift yönlü gidiş söz konusudur. Yani akılcılık anlayışı varlık anlayışını, varlık anlayışı da akılcılık anlayışını belirler.

Somut karakterli akılcılığa göre bir bütünü oluşturan parçaların gerektirici bir biçimde birbirleriyle bağlantısı kurulur.Soyut karakterli akılcılığa göre ise, parçalardan birisi soyut karakterli olarak göz önüne alınıp diğer parçalardan ayrılır. Örneğin imanı meydana getiren, cüzlerin gerektirici bir biçimde birbirine bağlanarak imanın bütününü oluşturması somut karakterli akılcılığa göre söz konusudur.Imanın sadece kalp ile tasdik olarak kabul edilip bilgi ve amelin imandan ayrılması da soyut karakterli akılcılığa göre söz konusu olur. Keza somut karakterli akılcılığa göre bilginin fiil ile bağlantısı kurulurken, soyut karakterli akılcılığa göre ise bilgi ile fiil ayrılır.

Somut karakterli akılcılıkta ayetler ve hadisler itikadî problemlerle ilgili çokça kullanılır. Zira ayetler ve hadisler itikadî problemlerle ilgili olarak ne kadar çok kullanılırsa, o ölçüde yorumlanmamış ve mecazî mânâda kullanılmamış olur. Bu da somut karakterli akılcılığın kullanıldığının delilidir. Buna mukabil soyut karakterli akılcılıkta ayet ve hadisler itikadî problemlerle ilgili olarak daha az kullanıldığından, yorumun ve mecazın kullanımı da o ölçüde fazla olabilmektedir. Bu da soyut karakterli akılcılığın kullanıldığının delilidir.

Somut karakterli akılcılıkta bir kelimenin anlamının Şarî̀in kastettiği mânâya göre oluşması söz konusu iken, soyut karakterli akılcılıkta ise aynı kelimenin anlamının onun lugat anlamı olarak kabul edilmesi söz konusudur. Zira bir kelimenin lugat anlamı, herkes için geçerli olan genel ve ortak bir anlamdir.

Somut karakterli akılcıllğa göre herhangi bir şeyle ilgili olarak değişim olgusu söz konusudur. Böylece o şeyle ilgili olarak artma, azalma ve derecelenme mümkün olur. Buna mukabil soyut karakterli akılcılık durağanlığı gerektirdiğinden herhangi bir şeyle ilgili olarak artma, azalma ve derecelenme söz konusu olmaz.

Somut ve soyut karakterli akılcılık üzerinde kısaca durduktan sonra, hadisçilerin iman esaslarının sayısı, neler olduğu ve bu esasların anlaşılmasına ilişkin görüşlerini ortaya koymak için onların iman probleminde metod olarak kullandıkları akılcılığı ve buna uygun olarak ortaya koydukları çözümleri görmemiz gerekir. Hadisçiler imanı söz ve 'amel olarak tanımlamışlardır. 
İmanı meydana getiren bu iki unsurdan söz ile kalbin tasdîki ve dilin ikrârı, amel ile de kalbin eylemi ve organların eylemi kastedilmiştir ${ }^{3}$. Şimdi de bunlar üzerinde kısaca duralım.

1. Kalbin Tasdîki: Kalpte olan imanın birisi kalbin tasdiki diğeri de kalbin bilgisi olmak üzere iki unsuru vardır. Her iki unsura birden kalbin sözü denir. Yani tasdik ile bilgi arasında sıkı bir ilişki vardır. İmanı sadece kalbin tasdikinden ibaret olarak görmek hadisçilere göre yanlıştır. Dolayısıyla tasdikin iman ile aynı anlamda olmadığı ortaya konurken, imanın zıddının tekzîb olmadığı hususuna dayanılmaktadır.

Tasdik, tekzîbin zıddıdır. Fakat tekzîb, imanın zıddı olmadığından tasdik ile iman eşanlamlı olmamaktadır. Diğer taraftan imanın zıddı küfürdür. Küfür, tekzîb ile aynı anlama gelmediğinden, imanın da tasdik anlamına gelmemesi gerekir. Zira tekzîb ile tasdik zıt anlamlıdır ${ }^{4}$. İmanın sadece tasdikten ibaret olmaması, imanın somut karakterli olmasının bir göstergesidir. İmanın somut karakterli olması da, bu somut karakterliliği ortaya koyan akılc1lığın somut karakterli olması anlamına gelir. Yani imanı oluşturan parçaları birbirine bağlayarak onu bir bütün olarak gören, somut karakterli akılcılıktir.

Hadisçilere göre tasdikin kendisinde de farklılaşma yani artma ve azalma vardır. Keza bu da imanın somut karakterli olduğunun bir başka göstergesidir. İnsanların tasdiklerinin birbirinden farklı olduğu şöyle izah edilir: Nasıl ki canlılar kudret ve irade gibi sıfatlar bakımından birbirinden farklı iseler, tasdik ile ilim bakımından da birbirinden farklıdırlar. Bir şeyin bilinmesi hususunda insanların birbirinden farklı olmadığını söylemek, bir şeyin görülmesi hususunda insanların birbirinden farklı olamayacağını söylemek gibidir. Nasıl ki ayın görülmesi hususunda insanlar arasında farklılık varsa, insanların tasdiki ve ilmi de birbirinden farklıdır. İnsanlar arasında ayın görülmesi hususunda bir ortaklık varsa da bazısının görmesinin diğerinden daha iyi olması bakımından aralarında farklılık vardır. Hatta kalbin tasdiki ve bilgisi bakımından insanlar arasındaki farklılık daha da fazladır ${ }^{5}$.

Hadisçilere göre kalbin sözü, kalbin tasdiki ve kalbin bilgisinden oluşuyordu. Tasdike ilaveten bilgi de hem imandır hem de bütün olan imandan bir parçadır. Tevhidi duyup da onu tasdik eden bir kimse sonra bunu delillerle de bilmek isterse bu durumda istidlâllerde bulunacaktır. İşte o kimse-

3 Ibn Teymiyye, Mecmu'u Fetava Ahmed b. Teymiyye, cem've tertîb: 'Abdurrahman b. Muhammad b. Kâsım ve oğlu Muhammed, c.: 1-37, tarihsiz, c. 7, s. 171.

4 A.g.e., c. 7, s. 292.

5 Ibn Teymiyye, Mecmu'u Fetava Ahmed b. Teymiyye, c. 7, s. 564-5. 
nin imanı istidlâli bir imandır ${ }^{6}$. Tasdike ilaveten bilginin de iman olması keza somut karakterliliğin bir göstergesidir.

Bilgi, iman olduğundan, bilgideki artma imandaki artma anlamına gelecektir ki bu da yine somut karakterliliğin bir başka göstergesidir. Bilgideki artma şöyle izah edilebilir: Allah'ın isimlerini ve mânâlarını bilip de onlara iman eden bir kimsenin imanı bu isimleri ve mânâlarını bilmeyen veya bazısını bilip de onlara mücmel olarak inananın imanından daha kâmildir. Yani insanın Allah'ın isimleri, sıfatları ve ayetlerine dair bilgisinin artması, o kimsenin imanının kâmil olduğu anlamına gelir.

Hadisçilere göre bilgideki artı̧̧ sadece bilmek açısından değil, bilginin ameli gerektirmesi bakımından da söz konusudur ki yine bu da somut karakterliliğin bir göstergesidir. Sahibinin kendisiyle amel ettiği bilgi sahibinin kendisiyle amel etmediği bilgiden daha kâmildir. Diğer taraftan Fâtır Sûresi 28. ayette Allah'tan korkanların âlimler olduğu belirtilmektedir. Madem ki Allah'tan korkanlar Kur'an'da övülenlerdir, o halde bu kimseler zemme müstehak değillerdir. Zemme müstehak olmamaları da gerekli olan fiilleri yapmalarıyla gerçekleşecektir ${ }^{7}$. Böylece ilim ile amel arasında bağlantı kurulmaktadır. Ancak ayet, belli bir tür akılcılığa yani somut karakterli akılcılığa göre yorumlanmıştır. Halbuki anlambilim açısından ayette böyle bir anlam söz konusu değildir.

Bilgideki artış, bilginin kendisiyle ve bilgi ile amel arasında kurulan bağla gerçekleştiği gibi, bilginin hatırlanmasıyla da gerçekleşir. Zira gaflet, bilginin gerçekleşmesini engeller. Gafil olduğu halde bir şeyi bilen bir kimsenin bu bilgisi, onu hatırlayanın bilgisinden daha azdır ${ }^{8}$. Yani hatırlamaya bağlı olarak bilgi gerçekleşmekte dolayısıyla bilgide artış meydana gelmektedir ki, bu da somut karakterliliğin bir göstergesidir. Keza hatırlama ile fiil arasında bağın kurulması da yine somut karakterliliğin bir ifadesidir. Gafir Sûresi 13. ayetin hatırlama ile fiil arasındaki bağı gösterdiği ifade edilmiştir. Zira tam bir tezekkür, tezekkür edilene tesiri gerektirir. Bir kimse sevileni tezekkür ederse onu talep eder, korkulanı tezekkür ederse ondan uzaklaşır ${ }^{9}$. Ancak ayetin tezekkürün fiili gerektirmesi biçiminde anlaşılması bize göre bir yorumdur. Zira ayette çokça Allah'a yönelenin tezekkür edeceğin-

6 Halîmî, Kitâb al-minhâc fî şu'abi'l-îmân, c.: 1-3, tahkîk: Hilmi Muhammad Fudah, 1979, c. 1, s. 25.

Ibn Teymiyye, Mecmu'u Fetava Ahmed b. Teymiyye, c. 7, s. 21.

A.g.e., c. 7, s. 566 .

Ibn Teymiyye, Kitâbu'l-îmân, tahkîk: es-Seyyid Muhammed Bedruddîn al-Na'sanî al-Halebî, M1sir 1325, s. 93. 
den bahsediliyor. Yoksa tezekkürün fiili gerektirmesinden değil. Dolayısıyla ayet belli bir tür akılcılığa yani somut karakterli akılcılığa göre anlaşılmış ve delil olarak kullanılmıştır.

2. Dilin İkrârı: Kalbin tasdikten başka imanın bir diğer unsuru da dilin sözüdür. Dilin sözünün imanın bir unsuru olması, doğal olarak somut karakterliliğin bir göstergesidir. İkrârın iman olduğu şöyle ispatlanır: Kâfir olan bir kimse itikad ve ikrâr ettiğinde mü'min olur. Bundan sonra namaz dişında şehadet kelimesini söylemesi gerekmez. Ancak kendi durumuyla (mü'min olup olmamasıyla) ilgili birtakım şüpheler ortaya çıkar ve bu şüpheleri gidermeye ihtiyaç hissederse 'Ben müslümanım' demesi kâfidir. Yoksa şehadet kelimesini söylemesi yani ikrarı gerekli değildir. Bundan ikrarın iman olduğu anlaşılmaktadır. Zira şehadet kelimesi iman olmayıp, o kimsenin hali ve durumuna delâlet eden bir şey olsaydı, o takdirde durumunda karışıklık olduğu her halde şehadet kelimesini söylemesi gerekirdi ${ }^{10}$. Bu, gerekli olmadığına göre ikrârın iman olduğu anlaşılmış olur. Ancak burada problemli bir durum vardır. Zira başlangıçtaki küfürden imana geçme durumu göz önüne alınarak ikrârın iman olmasından söz edilmiştir. Halbuki hadisçilere göre imanda artma ve azalma olduğundan ikrarın çokluğu ile imanda artma, ikrarın azlığı ile de imanda azalma olmalıdır. Dolayısıyla ikrarın iman olması sadece başlangıçtaki durum için değil, daha sonraki durumlar için de söz konusu olmalıdır.

3. Kalbin Ameli: Kalp ameli ile Allah'ı ve Resûlünü sevmek, Allah'tan korkmak gibi fiiller anlaşılmaktadır. İnsanın mü'min olması için Allah'ın ve Resûlünün, onların dışındakilerden o kimseye daha sevgili olması gerekir. İbn Teymiyye kalp fiillerini imanın gereği olarak görüyor. İnsan mü’min olduğunda aksine bir kasıt olmadıkça, kalp fiilleri gerekli olur ${ }^{11}$. Ancak burada problemli bir durum vardır. Kalp fiilinin gerekli olmasının delili nedir? Zira aksine bir kasıt olmadan bir şeyin meydana gelmesi, onun gerekli olarak meydana geldiğini göstermez. Yani aksine bir kasıt olmadan bir şey gerekli olarak değil de doğal olarak da meydana gelebilir. Bu takdirde kalp fiili tasdikten ayrılmış olur. Dolayısıyla kalbin tasdikinin kalp fiilini gerekli olarak meydana getirmesinin somut karakterli akılcılığın bir göstergesi olduğu söylenebilir.

Mücadele Sûresi 22. ayet, kalp fiili için delil olarak kullanılmıştır ${ }^{12}$. Ancak ayetin kalp fiiline delil olarak kullanılması problemlidir. Ayete göre Al-

\footnotetext{
Halîmî, Kitâbu'l-minhâc fỉ şu'abi'l-îmân, c. 1, s. 29.

Ibn Teymiyye, Mecmu'u Fetava Ahmed b. Teymiyye, c. 7, s. 16.

12 Ibn Teymiyye, Mecmu'u Fetava Ahmed b. Teymiyye c. 7, ss. 14-16.
} 
lah'ın düşmanlarını sevmek ile iman bir arada olmaz. Fakat hadisçilere göre kalp fiili hem imandır hem de bütün olan imanın bir parçasıdır. O halde hadisçilere göre ya kalp fiilinin olmamasından dolayı imanın tümü ortadan kalkacaktır ya da imanın bir kısmı kalacaktır. İmanın tümü ortadan kalkarsa o takdirde iman, sadece kalp fiiline bağlı olmuş olur ki bu, hadisçilerin görüşüne aykırıdır. Yok eğer imanın bir kısmı kalırsa, o zaman da ayetin ifade ettiğinin tersine bir anlam söz konusu olacaktır. Zira ayete göre Allah'ın düşmanlarını sevmek ile iman bir arada olamaz.

Hadisçilere göre kalp fiilinin imanı oluşturan unsurlardan birisi olarak görülmesi ve kalbin tasdiki ile organların fiilini birbirine bağlaması somut karakterliliği gösterir. Zira insanlar tasdikte ve bilgide eşit olmayıp farklılaşmaya tâbi oldukları gibi, sevgi ve korkuda da eşit olmayıp farklılaşmaya tâbidirler.

4. Organların Ameli: Hadisçilere göre organlarla yapılan ameller imana dahildir. Buna şöyle delil getirilir: Madem ki herhangi bir ibadeti yalanlamak küfürdür, o halde ihlas ile bu ibadetin yapılması imanın cüzlerinden birisidir ${ }^{13}$. Ancak burada problemli bir durum vardır. Zira ibadetin yalanlanmasının zıddı olarak ibadetin yerine getirilmesi anlaşılıyor. Halbuki ibadetin yalanlanmasının zıddı olarak ibadetin tasdik edilmesinden bahsedilebilir. Dolayısıyla böyle bir delil somut karakterli akılcılığa göre ortaya konmuş oluyor.

İbn Teymiyye amelleri imandan bir parça olarak gördügünden, amellere mecazî olarak iman denmesine karşı çıkar. Yani amellere mecazî olarak iman denmiş olsa, o takdirde ameller imanın bir parçası olmazlar. Dolayısıyla amellere hakîkat anlamında iman denir. İbn Teymiyye amellere mecazî olarak iman denmemesinin delili olarak hakîkat-mecaz ayırımının hicrî 3. yüzyıldan sonra ortaya çıktığını belirtmiştir ${ }^{14}$. Yani başlangıçta amellere hakîkat anlamında iman denmiştir. Ancak amellerin mecazî mânâda iman diye isimlendirilmesine karşı çıkılırken bir bakıma amellerin hakîkat mânâsında iman diye isimlendirilmesine de karşı çıkılmış olunmaktadır. Zira mecazî mânâyı belli bir tür akılcılığa göre kabul ediyorsak hakîkat mânâyı da belli bir tür akılcılığa göre kabul ediyoruz demektir. Dolayısıyla mecazîn ${ }^{15}$ mânânın kabul edilmemesi yönündeki itiraz problemli görünmektedir. Ayrıca dinî bir kelimenin anlamının belirlenmesinde hakîkat ve mecaz anlamlarından

3 Halîmî, Kitâbu'l-minhâc fì şu'abi'l-îmân, c. 1, s. 38.

14 Ibn Teymiyye, Mecmu'u Fetava Ahmed b. Teymiyye, c. 7, s. 88.

15 Buradaki hakikat mânâ mecazın karşıtı anlamında olmayıp, hadisçilerin anlayışına göre oluşan hakikat mânâdır. 
birisinin kabul edilmesi zorunlu değildir. Bu mânâlardan başka şekilde de iman kelimesine anlam verilebilir. Zira bir kelimeye anlambilime göre verilen anlam, o kelimenin hakîkat ve mecaz mânâsı olmayabilir.

Hadisçiler amellerin imandan olması hususunda bir tür akılcılık doğrultusunda ayetleri anlamaktadırlar. Örneğin mü'minlerin, Enfâl Sûresi 2. ve 3. ayetlerdeki fiilleri birleştirdiklerinden bahsedilmektedir ${ }^{16}$. Dolayısıyla söz konusu ayetlerdeki fiiller, imanı oluşturan parçalardır. Yani belli bir tür akılcllıkla söz konusu fiillerin imandan olduğu benimsenmiş oluyor. Zira söz konusu fiillerin birleştirilmesine ve bu fiillerin imandan olduğuna dair dilsel bir ifade yoktur. Yani söz konusu ayetler somut karakterli akılcılığa göre anlaşılmış olmaktadır. Zira ayetlerin anlambilime göre anlaşılması, ayetlerin dilsel ifadelerinden hareketle birtakım anlambilimsel kriterlere göre anlaşılması demektir.

İmanın aslı ve kollarının birbirini gerektirmesi ${ }^{17}$ anlamında da somut karakterli akılcılıktan bahsedilebilir. Bu tür akılcılığa göre kalpte tasdik ve buna bağlı olarak kalp fiili gerçekleştiğinde bedenin de söz ve amel bakımından harekete geçmesi gerekir. Bu, böyle olduğu gibi bunun tersi de söz konusudur. Yani bedende gerçekleşen söz ve amelin imanın kalpteki yönü üzerinde tesiri vardır. İmanın iki ve daha çok yönünün karşılıklı olarak birbirine tesir etmesinin gerekliliği, somut karakterli akılcılığın bir göstergesidir. Çünkü tek yönlü bir gerektirmede somut-karakterlilik söz konusu olmayabilir. Zira tek yönlü gerektirme sebep ile müsebbeb arasında söz konusu olabilir ve sebep müsebbebden ayrilabilir.

Buraya kadarki açılklamalara göre, hadisçiler hem parçaya hem de parçaların oluşturduğu bütüne iman dediklerinden ve imanda artma ve azalmayı kabul ettiklerinden somut karakterli bir iman anlayışına sahiptirler. İman anlayışları somut karakterli olduğundan hadisçiler açısından 'iman esasları' ile imanı oluşturan parçalar da kastedilmiştir. Yani bütünü oluşturan her parça bir iman esası olmaktadır. Bu durumda hadisçiler, iman esaslarının sayısını, neler olduğunu ve anlaşılma biçimini kullandıkları somut karakterli akılcılığa ve imanın şubelerinden bahseden hadisi esas alarak tespit ediyorlar. Böylece hadisçiler iman esaslarını 70 küsur şubeye kadar çıkarmakta ve bu şubeleri somut karakterli olarak anlamakta, yani bu esasların tasdik, bilgi ve amellerle bağlantısını kurmaktadırlar. Ancak iman esaslarının 70 küsur şubesini tek tek saymak bu makalenin amacı olmadığından bu şubeleri burada zikretmekten kaçınıyoruz.

16 Halîmî, Kitâbu'l-minhâc fì şu'abi'l-îmân, c. 1, s. 34 .

17 Ibn Teymiyye, Mecmu'u Fetava Ahmed b. Teymiyye, c. 7, s. 541-2. 
İman esaslarının sayısı, neler olduğu ve anlaşılma biçimini tespit etmek için kelâmcıların 'iman esasları' anlayışlarını ortaya koymak gerekir. Dolayısıyla iman probleminde kullandıkları akılcılığı ve buna göre getirdikleri çözümleri görmek mümkün olur. Genelde ehl-i sünnet olarak bilinen kelâmc1lar, imanın kalp ile tasdik olduğu görüşündedirler. Zira dilciler imanın kalp ile tasdik olduğu hususunda müttefiktirler. Ebu'l-Muîn en-Nesefî, imanın tasdikten başka bir şey olduğunu söylemenin, bir kelimenin dilde bilinen mânâsını bilinmeyen başka bir mânâya nakletmek olduğunu ve eğer böyle bir duruma cevaz verilecekse dildeki her kelime için bunun söz konusu olabileceğini dolayısıyla dilin iptal edilmiş olacağını, bunun ise muhal olduğunu ifade etmiştir ${ }^{18}$.

Kelâmcı, imanın lugat mânâsı olan tasdik ile dindeki anlamı arasında bir ayırım yapmaz. Yani imanın dildeki mânâsı aynı zamanda dindeki anlamıdır. Dolayısıyla imanın dildeki mânâsını onun şeriattaki anlamı olarak kabul etmemiz zordur. İmanın hakikati ile imanın taalluk ettiği şeyleri birbirinden ayırabiliyorsak o takdirde 'iman esasları' ile imanın hakikati kastedilmiş olamaz. Zira 'iman esasları' çokluğu ifade eder. Halbuki imanın hakikati çokluğa müsait değildir. O halde 'iman esasları' ile imanın taalluk ettiği şeyler yani iman edilecek hususlar kastedilmelidir. İmanın hakikatinde herhangi bir değişme söz konusu olmamasına karşın iman edilecek şeylerde yani iman esaslarında değişmeden söz edilebilir. İman esaslarının tespiti de bu konuda izlenecek metod ve kriter olarak alınacak şeyle bağlantılıdır. Örneğin iman esaslarının tespitinde soyut karakterli akılcılığa ilaveten bu konuda mütevatir hadis olmadığ 1 için sadece Kur'an kriter olarak alınabilir.

Kur'an'da iman esasları üç kaideye göre ortaya konmaktadır: 1. İman esasları ortaya konmuş ve onlara iman edilmesi emredilmiştir. 2. Bu esasları inkâr edenler veya onlara inanmayanlar yerilmiştir. 3. Bu esasları kabul edenler övülmüştür. Bu üç kriter göz önüne alındığında Kur'an'da iman esaslarının 5 olduğu tespit edilmektedir: 1 . Allah'a iman, 2. Meleklere iman, 3. Kitaplara iman, 4. Peygamberlere iman, 5. Ahiret gününe iman. Örneğin Kur'an'da Allah'a iman, bazen Allah'a inanınız şeklinde emir suretiyle, bazen Allah'a inananları övmek suretiyle bazen de Allah'a inanmayanları yermek suretiyle ortaya konmuştur. Nisâ, 171; Âl-i İmran, 179; Tegâbun, 11; Yunus, 106. ayetlerde olduğu gibi. Kur'an iman esaslarını Nisâ Sûresi 136. ayet ile Bakara Sûresi 177. ayette toplu olarak bir arada da zikretmiştir ${ }^{19}$.

18 Ebu Mu'în en-Nesefî, Tabsiretu’l-Edille, tahkîk: Claude Salamé, c.: 1-2, Dimaşk 1993, c. 2, s. 789.

19 Atay, Hüseyin, Kur'an'da Iman Esaslart, Ankara 1998, ss. 25-29. 
Diğer taraftan soyut karakterli akılcılık yanında Cibrîl hadisi göz önüne alınarak da iman esaslarının tespiti yapılmıştır. Buna göre ise iman esaslarının sayısı altı olup, onlar da şunlardır: 1. Allah'a iman, 2. Meleklere iman, 3. Kitaplara iman, 4. Peygamberlere iman, 5. Ahiret gününe iman, 6. Kadere iman. Böylece kelâmcılar açısından iman esaslarının sayısı ve neler olduğu bu şekilde de tespit edilebilir.

Kelâmcılar iman esaslarını sadece kalp ile tasdik edilmeleri itibariyle göz önüne alıp, bu esasların bilgi ve amelle bağlantısını kurmuyorlar. Zira kelâmcllara göre iman, kalp ile tasdik olmakla hem bilgi hem de amel imandan ayrılmış olmakta dolayısıyla iman soyut karakterli olarak kabul edilmektedir. Bilgi imandan başka bir şeydir. Zira bir şeyi bilmeyenin onu yalanlamayla vasıflandırılması veya aksine bir şeyi bilen bir kimsenin onu tasdik etmekle vasıflandırılması söz konusu değildir. Yani bir şey hususunda cahil olana o şeyi yalanlayıcı denmediği gibi, bir şeyi bilene de onu tasdik edici denmez ${ }^{20}$.

Bilgi imandan başka bir şey olduğu gibi amel de imana dahil değildir. Meselâ Bakara Sûresi 183. ayette ve Hucurat Sûresi 1. ayette olduğu gibi mü'mine bazı şeylerin emredilmesiyle ve mü'minin bazı şeylerden nehyedilmesiyle imanlı olma ile bazı şeylerin emredilmesi ve nehyedilmesi birbirinden ayrılmış olmaktadır ${ }^{21}$. Yani kendisinde iman bulunandan bir şey yapması istendiğine ve o kimse bir şeyden nehyedildiğine göre iman ile amel farklı şeyler olmaktadır. Dolayısıyla iman esaslarının sayısı, neler olduğu ve bu esasların anlaşılma biçimi birtakım kriterlere ilave olarak sadece kalp ile tasdik edilmeleri itibariyle de göz önüne alınmıştır.

Sonuç olarak hem hadisçiler hem kelâmcılar kullanmış oldukları akılcılığa ve koydukları birtakım kriterlere göre iman esaslarını tespit edip anlamışlardır. Halbuki Kur'an'ı anlambilime göre anlamaya çalıştığımızda iman esaslarının tespiti ve anlaşılma biçimiyle ilgili bir bilginin Kur'an'da mevcut olmadığını görüyoruz. Yani iman esasları konusunda ortaya konan çözümler birer yorumdur. Dolayısıyla bu konudaki farklılıkları doğal karşılamak gerekir.

Maturîdî, Kitâbu't-Tevhîd, tahkîk: Fathullah Hulayf, İstanbul 1979, s. 612-3.

${ }^{21}$ Taftazânî, Şerhu'l-Makasıd, tahkîk: 'Abdurrahman 'Umayre, c.: 1-5, Beyrut 1989, c. 5, s. 177. 